\title{
Ectopic Pregnancy and Ultrasound: A Review
}

\section{Raydeen M Busse}

Assistant Professor, Department of Obstetrics and Gynecology, and Women's Health John A Burns School of Medicine, University of Hawaii, Honolulu, Hawaii

Correspondence: Raydeen M Busse

Assistant Professor, Department of Obstetrics and Gynecology, and Women's Health, John A Burns School of Medicine

University of Hawaii, 1319 Punahou Street, Honolulu, Hawaii 96826, USA

Phone: 808-983-8391, E-mail: rbusse@hawaii.edu

\begin{abstract}
First trimester bleeding occurs in up to $30 \%$ of all diagnosed pregnancies. Important causes of first trimester bleeding include spontaneous abortion, missed or threatened abortion, ectopic pregnancy, and gestational trophoblastic disease. One of the greatest dilemmas for clinicians is to accurately diagnose the cause of pain or bleeding, and specifically to determine if an ectopic pregnancy exists due to its grave consequences. Ectopic pregnancy occurs in almost two percent of all reported pregnancies in the United States and is the leading cause of pregnancy-related death in first trimester. When an early pregnant patient is identified who has bleeding or pain, it is crucial step to determine where the pregnancy is located. Ultrasound as a first line diagnostic tool offers an excellent opportunity for pregnancy localization. The use of the beta subunit of human chorionic gonadotropin (beta-hCG) quantification is a valuable adjunct to help determine the course and possible outcome of an early pregnancy. The goal should be to preserve the health and future reproductive capabilities of our patients.
\end{abstract}

Key words: Ectopic pregnancy, ultrasound, beta-hCG, Doppler.

Learning objectives

- To know the accuracy of ultrasound in the diagnosis of ectopic pregnancy

- To understand the use of the beta-hCG subunit in the context of ultrasound.

\section{INTRODUCTION}

An ectopic pregnancy is any pregnancy that occurs outside the uterine cavity; and is a significant cause of morbidity and mortality in women. It occurs in nearly 2 percent of US pregnancies and is the leading cause of pregnancy-related death in first trimester. Ruptured ectopic pregnancies account for 10 percent of all maternal deaths. In addition, the incidence of ectopic pregnancies in the United States rose from less than 0.5 percent of all pregnancies in 1970 to 2 percent in 1992 and this number may be rising. ${ }^{1-3}$
Risk factors associated with ectopic pregnancy include prior ectopic pregnancy, fallopian tube surgery, prior upper genital tract infection, and infertility especially if associated with assisted reproductive technologies. A more recent review ${ }^{4}$ summarizes the risks (Table 1). ${ }^{4-10}$ The clinician's challenge is to obtain an early diagnosis of ectopic pregnancy so that morbidity and mortality may either be eliminated or minimized. ${ }^{11}$

With the increasing use of transvaginal sonography (TVS) since 1987 and more accurate beta-hCG tests, the mortality from ruptured ectopic pregnancies has been significantly reduced from a death rate of $35.5 / 10,000$ ectopic pregnancies in 1970 to 3.8/10,000 in $1989 .{ }^{11}$ High-resolution transvaginal ultrasonography detects the gestational sac of an intrauterine pregnancy (IUP) by 32 to 35 days of gestation. ${ }^{12}$ Early detection before rupture of the fallopian tube can offer the opportunity for outpatient treatment, reducing the risk of complications and impaired future fertility. A delay in diagnosis might result in tubal rupture, subsequent intra-abdominal hemorrhage, need for laparotomy, blood transfusion, and death.

\section{Ultrasound Alone}

Multiple studies have been performed to determine what criteria should be used to positively identify with the greatest accuracy, a woman's risk of having an ectopic pregnancy. The use of ultrasound alone has a sensitivity of nearly $100 \%$ in diagnosing an intrauterine pregnancy as early as 5.5 gestational weeks. ${ }^{13,14}$ Brown et al in 1994 found that using a less strict criteria of transvaginal sonography visualization of any adnexal mass other than a simple cyst had high specificity $(98.9 \%)$ and positive predictive value (96.3\%) and a better sensitivity $(84.4 \%)$ and negative predictive value (94.8\%) than using other ultrasound criteria such as an extrauterine gestation, gestational sac, yolk sac, or "tubal ring" sign in diagnosing an ectopic pregnancy (Figs 1 and 2).${ }^{15}$ This is felt to be true due to the fact that only 20 to $25 \%$ of ectopic pregnancies present with visualization of an extrauterine embryo (Figs 3 to 5). In addition, the presence of 
Ectopic Pregnancy and Ultrasound: A Review

\begin{tabular}{lll}
\hline & Table 1: Risk factors for ectopic pregnancy ${ }^{4-10}$ & \\
\hline & Adjusted OR (95\% CI) & OR (95\% CI) \\
\hline Previous tubal surgery & $4.0(2.6-6.1)$ & $4.7-21.0$ \\
Infertility (risk increases with length of infertility) & $2.1-2.7$ & $2.5-21.0$ \\
Previous genital infection confirmed & $3.4(2.4-5.0)$ & $2.5-3.7$ \\
Previous miscarriage & $3.0(>2)$ & - \\
Previous induced abortion & $2.8(1.1-7.2)$ & -1.7 \\
Past or ever smoker & $1.5(1.1-2.2)$ & $(1.8-3.4)$ \\
Current smoker (risk increase with amount smoked per day) & $1.7-3.9$ & $2.3-2.5$ \\
Age 40 years and older & $2.9(1.4-6.1)$ & - \\
Intrauterine device use (> 2 years) & $2.9(1.4-6.3)$ & $4.2-45.0$ \\
Previous IUD & $2.4(1.2-4.9)$ & - \\
Sterilization & - & $9.3(4.9-18.0)$ \\
Previous ectopic pregnancy & - & $8.3(6.0-11.5)$ \\
Documented tubal pathology & $3.7(1.2-4.8)$ & $2.5-3.5$ \\
More than one sexual partner & - & $2.1-2.5$ \\
Diethylstilbestrol exposure & - & $5.6(2.4-13.0)$ \\
\hline
\end{tabular}

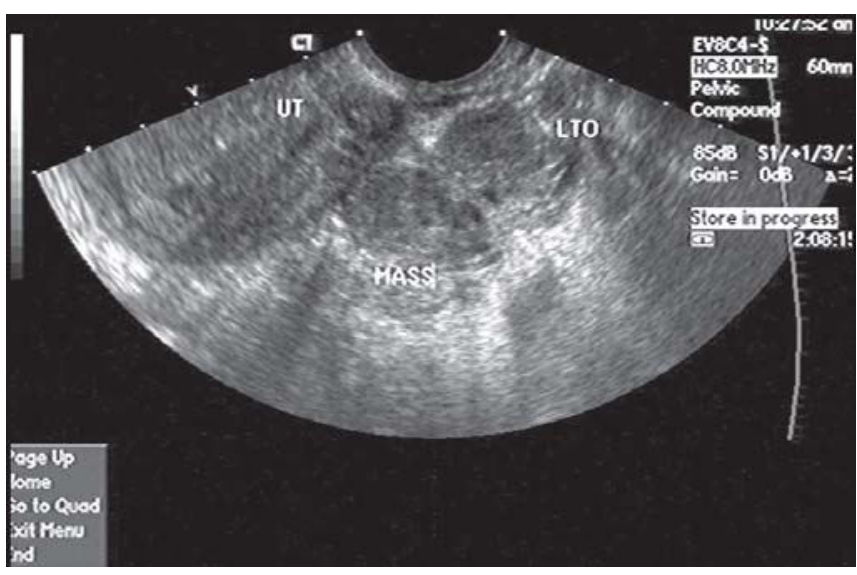

Fig. 1: Transvaginal sonography of the "blob sign" seen as a heterogeneous adnexal mass adjacent to a normal left ovary and situated in-between the uterus

a pseudosac has also come into question as a criterion for presumed ectopic pregnancy. Ahmed's study in 2004 showed that a number of patients with a pseudosac did not have an ectopic pregnancy, and conversely, a number of patients with an ectopic pregnancy did not have a pseudosac. ${ }^{16}$

A brief mention should be made on heterotopic, cervical and abdominal pregnancies. $95 \%$ of all ectopic pregnancies are tubal in location but $2 \%$ are interstitial or cornual, $2 \%$ are ovarian and $1 \%$ are cervical or abdominal. ${ }^{17}$ There are now more reports in the literature on cesarean section scar pregnancies as well as heterotopic pregnancies which also have increased ( 0.3 to $1 \%$ of all pregnancies) due to assisted reproductive technologies. ${ }^{18-24}$ Women who have histories that might increase their

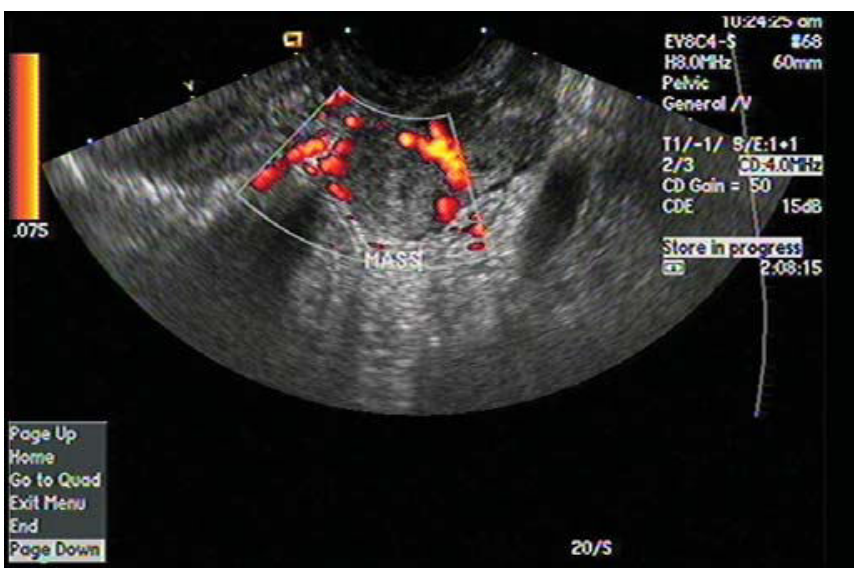

Fig. 2: Same patient as Figure 1 with power Doppler flow demonstrating the "tubal ring" sign surrounding the adnexal mass/ectopic pregnancy

risk for these types of pregnancies should have special scrutiny during ultrasound as they tend to be diagnosed later in gestation.

\section{Serum Beta-hCG Alone}

Following serial beta-hCGs alone has also been studied and the previously accepted $15 \%$ decline in 7 days (which is used to follow treated ectopic pregnancies) is probably too slow of a decline to be considered normal in a spontaneous miscarriage or tubal miscarriage. ${ }^{25}$ Barnhart found the slowest rate of decline-described by the 95th percentile-ranged from 21 to $35 \%$ decline in 2 days and 60 to $84 \%$ in 7 days. ${ }^{26}$ This led the authors to conclude that for patients whose pregnancies were expected to resolve spontaneously, a $15 \%$ decline in 7 days 


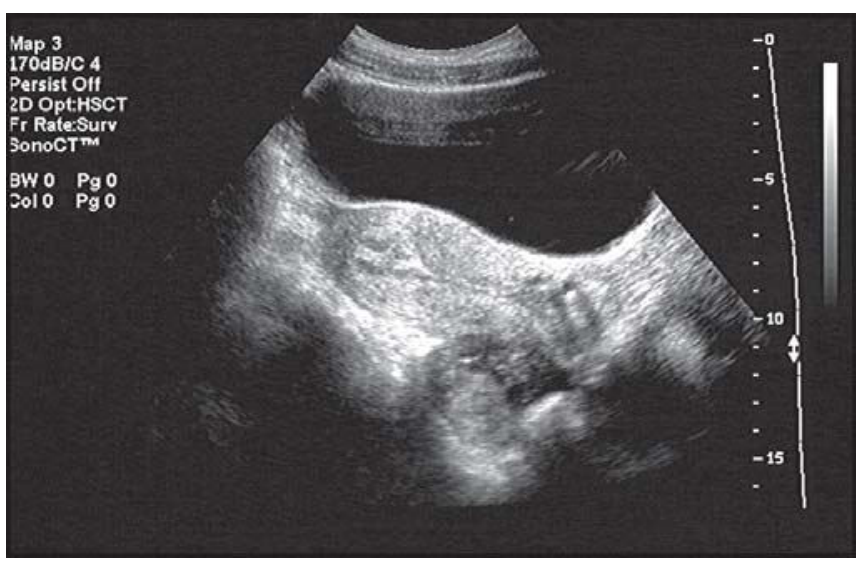

Fig. 3: Transabdominal sagittal view of the uterus with a cul-de-sac mass (ectopic pregnancy)

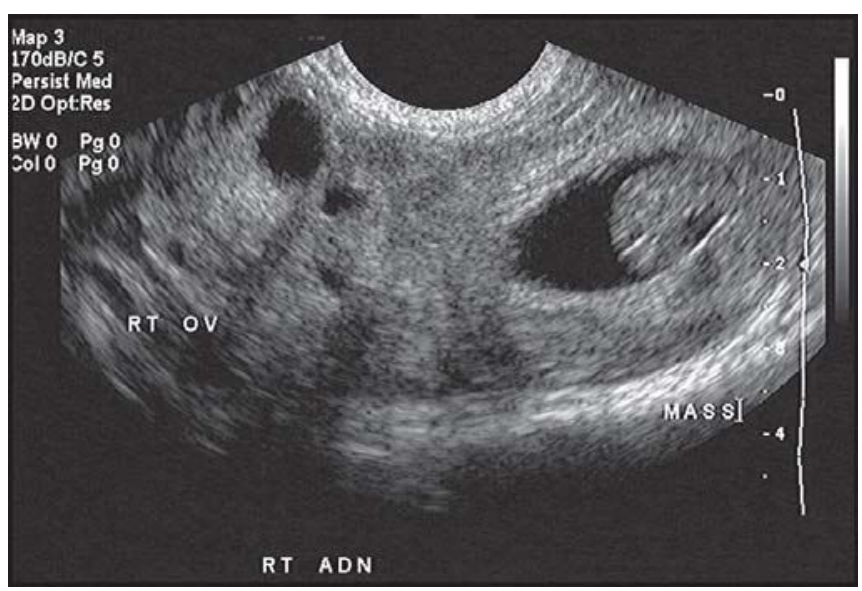

Fig. 4: Transvaginal view of the same patient as Figure 3 with a normal right ovary and adjacent ectopic pregnancy with live embryo

was slower than the newly graphed expected rate and should prompt intervention to eliminate the possibility of an ectopic pregnancy.

Most recently, the study of beta-hCG levels in a large population has shown that the slowest increase associated with a viable intrauterine pregnancy is $53 \%$ after 48 hours rather than the traditionally quoted $66 \%$ rise in 48 hours. $^{27}$

\section{COMBINING ULTRASOUND AND BETA-hCG LEVELS}

Due to the above controversies and fallibilities of using ultrasound alone or serum testing alone, many authors now conclude that a combined approach of using measurements of beta-hCG and incorporating transvaginal sonography may have an improved sensitivity of $97 \%$ and $96 \%$ specificity which could significantly decrease the need for invasive tests and unnecessary laparoscopies/laparotomies. 4,28,29

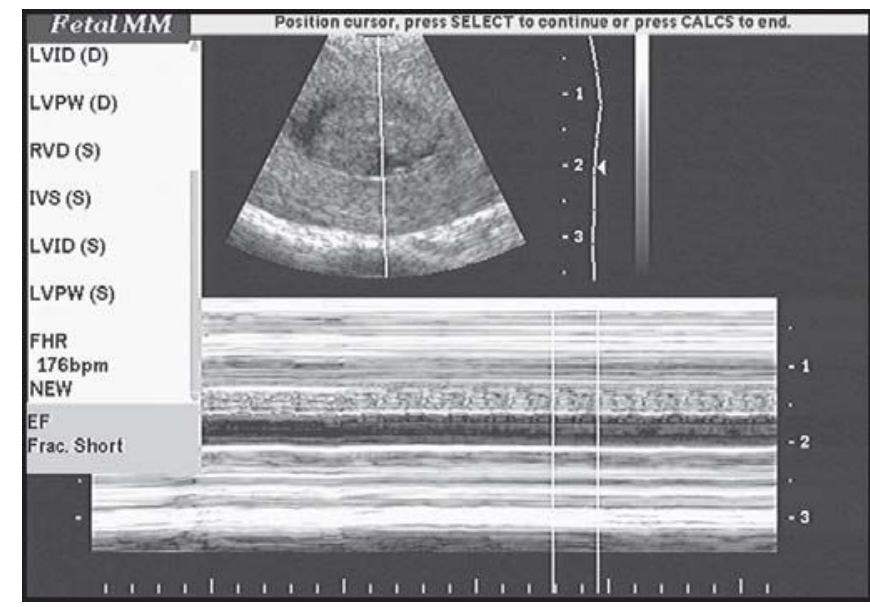

Fig. 5: Same patient as Figures 3 and 4 ultrasounds with live embryo's fetal heart tone demonstrated

The advent of highly sensitive testing of serum beta-hCG levels has led us to accept that when the level was greater than or equal to $2,000 \mathrm{mIU} / \mathrm{ml}$ and an intrauterine pregnancy was not visualized by transvaginal sonography, an ectopic or nonviable pregnancy could be safely and accurately diagnosed..$^{30}$

This assumption has been put to the test, since Barnhart retrospectively looked at women who had presumed diagnoses of ectopic pregnancy due to a beta-hCG above $2000 \mathrm{mIU} / \mathrm{ml}$ without evidence of an intrauterine pregnancy by ultrasound or due to an abnormal rise or fall of serial beta-hCGs. ${ }^{31}$ They found that the presumed diagnosis of ectopic pregnancy was incorrect in nearly $40 \%$ of the cases, especially in women with hCGs above the discriminatory zone and no IUP visualized by ultrasound. These women had an equal chance of having a miscarriage or an ectopic pregnancy. Women who had plateaus in the hCG below the discriminatory zone were more likely to be diagnosed with an ectopic pregnancy, with the presumed diagnosis being wrong $30 \%$ of the time.

There is also some debate over the so-called discriminatory level at which an intrauterine pregnancy should be visualized by transvaginal sonography. ${ }^{28}$ Using the combined approach, this level may vary. It has been suggested that in the absence of a mass or fluid in the cul-de-sac, the discriminatory level of $2000 \mathrm{mIU} / \mathrm{ml}$ should be utilized and where there is the risk for multiple gestations, the level of $>2000 \mathrm{mIU} / \mathrm{ml}$ should be used before visualizing gestational sacs. ${ }^{32}$

As to what order of testing might be the most cost effective and accurate, Gracia and Barnhart looked at 6 different algorithms using transvaginal sonography and quantitative hCG values. ${ }^{33}$ The six algorithms involved the following: (i) ultrasound followed by quantitative hCG, (ii) quantitative hCG followed by ultrasound, (iii) progesterone followed by ultrasound and quantitative $\mathrm{hCG}$, (iv) progesterone followed by quantitative hCG measurement and ultrasound, (v) ultrasound followed by repeat ultrasound, and (vi) clinical 
examination. They found that the best decision tree was to perform transvaginal sonography on all women who presented with abdominal pain or bleeding in the first trimester. If the TVS was inconclusive, a beta-hCG was quantified and women were treated according to this level. This method produced the best outcome in that no ectopic pregnancies were missed and the smallest number (1\%) of potential intrauterine pregnancies was interrupted. In addition, the average time to diagnosis was 1.46 days. This algorithm was found to be equally effective in high and low-risk populations.

\section{DOPPLER/3D ULTRASOUND}

Doppler ultrasound has been investigated since 1990 as an adjunct to two-dimensional transvaginal sonography with the potential to make earlier diagnosis of ectopic pregnancies possible. Doppler studies of peak flow velocities and resistive indices have been investigated in both uterine and tubal arteries and copus lutei. Jurkovic in 1992 performed a prospective study of women with a singleton intrauterine pregnancy and women with an ectopic pregnancy and found that there was no difference in blood flow impedance in the uterine and spiral arteries and corpus luteum. ${ }^{34}$ The peak flow velocities in the uterine arteries were significantly higher in women with ectopic pregnancies, however; reflecting decreased blood supply to the uterus in ectopic pregnancies. Kirchler evaluated blood flow via Doppler on the tubal arteries on both sides in women with and without ectopic pregnancies. The results showed statistical significance in the mean between-side difference of tubal blood flow; meaning, there was a larger difference between the side of the ectopic pregnancy and the normal side as compared to between-side differences of two normal fallopian tubes in women with an intrauterine pregnancy. ${ }^{35}$ Salim looked at blood flow in the corpus lutei of normal, abnormal intrauterine pregnancies and ectopic pregnancies and found no statistical significance between ectopic, anembryonic or molar pregnancies and normal pregnancies. ${ }^{36}$ Atri also studied pregnancies to see if there was a difference in the resistive indices of an ectopic pregnancy and a corpus luteum cyst of pregnancy-both entities which can be confused with one another. ${ }^{37}$ He found that both high and low resistive indices discriminate ectopic pregnancy from a corpus luteum. Megier looked at 100 color and pulsed Doppler studies of tubal ectopic pregnancies and found that color Doppler facilitated the diagnosis of small ectopic pregnancies (gestational sacs $<1 \mathrm{~cm}$ and echogenic adnexal masses $<2 \mathrm{~cm}$ ) by detecting high impedence flow (diastolic index < 0.35). ${ }^{38}$ Most recently Ramanan described a new sign by Doppler ultrasound called the "leash sign" that has a sensitivity of $100 \%$ and specificity of $99 \%$, PPV $95 \%$ and NPV of $100 \%$ in the early diagnosis of ectopic pregnancy. ${ }^{39}$ It is described as an eccentric leash of vessels on color Doppler that showed a low resistance placental type of flow.
Transvaginal three- and four-dimensional sonography has had limited use thus far for visualizing ectopic pregnancies.

There have been case reports of using this modality for confirming the diagnosis of interstitial and cornual ectopic pregnancies as well as for the growing number of ectopic pregnancies in a cesarean section scar. This is due to the ability to see the uterus and endometrial cavity in the coronal plane view. ${ }^{40,41}$ The improvement in the spatial orientation is inherent in the use of three-dimensional sonography and has also been described as being useful in evaluating the endometrial stripe in cases of pregnancies of unknown location. Rempen described the presence of persistently distinct symmetry with regard to the median longitudinal axis of the uterus in the coronal plane in $90 \%$ of extrauterine pregnancies. This symmetry was lost in intrauterine pregnancies. ${ }^{42}$

\section{CONCLUSIONS}

It is clear that efforts to identify an ectopic pregnancy at an earlier stage will have an important impact on the morbidity and mortality of reproductive aged women. There have been tremendous life-saving changes in the diagnosis, management and outcome of ectopic pregnancies over the last 20 years due to improved technologies and on-going studies that evaluate newer technologies. Transvaginal sonography with or without the use of serum markers or Doppler has become the mainstay in the first-line evaluation of women suspected of having an ectopic pregnancy or in cases of pregnancies of unknown location.

\section{REFERENCES}

1. Goldner TE, Lawson H, Xia Z, Atrash H. Surveillance for ectopic pregnancy-United States, 1970-1989. MMWR Morb Mortal Wkly Rep 1993;42:73-85.

2. Centers for Disease Control and Prevention. Current trends ectopic pregnancy-United States, 1990-92. MMWR Morb Mortal Wkly Rep 1993;44:46-8.

3. Kriebs J, Fahey J. Ectopic Pregnancy. J Midwifery Women Health 2006;51:431-9.

4. Farquhar C. Ectopic pregnancy. Lancet 2005;366(9485):58391.

5. Ankum WM, Mol BWJ, Van der Veen F, Nossuyt PMM. Risk factors for ectopic pregnancy: a meta-analysis. Fertil Steril 1996;65:1093-9.

6. Bouyer J, Coste J, Shojael T, Pouly JL, Fernandez H, Gerbaud L, Job-Spira N. Risk factors for ectopic pregnancy: a comprehensive analysis based on a large case-control, populationbased study in France. Am J Epidemiol 2003;157:185-94.

7. Bouyer J, Rachou E, Germain E, Fernandez H, Coste J, Pouly JL, Job-Spira N. Risk factors for extrauterine pregnancy in women using an intrauterine device. Fertil Steril 2000;74:899908. 
8. Mol BWJ, Ankum WM, Bossuyt PMM, Van der Veen F. Contraception and the risk of ectopic pregnancy: a meta-analysis. Contraception 1995;52:337-41.

9. Xiong X, Buekens P, Wollast E. IUD use and the risk of ectopic pregnancy: a meta-analysis of case-control studies. Contraception 1995;52:23-34.

10. Fernandez H, Gerviase A. Ectopic pregnancies after infertility treatment: modern diagnosis and therapeutic strategy. Hum Reprod 2004;10:503-13.

11. Lozeau, AM, Potter, B. Diagnosis and management of ectopic pregnancy. Am Fam Physician 2005;72:1719-20.

12. Nyberg DA, Mack LA, Laing FC, Jeffrey RB. Early pregnancy complications: endovaginal sonographic findings correlated with human chorionic gonadotropin levels. Radiology 1988;167:61922.

13. Goldstein SR, Snyder JR, Watson C, Danon M. Very early pregnancy detection with endovaginal ultrasound. Obstet Gynecol 1988;72:200-4.

14. Timor-Tritsch IE, Yeh MN, Peisner DB, Lesser KB, Salvik BS. The use of transvaginal ultrasound in the diagnosis of ectopic pregnancy. Am J Obstet Gynecol 1988;161:157-61.

15. Brown D, Doubilet P. Transvaginal sonography for diagnosing ectopic pregnancy: positivity criteria and performance characteristics. J Ultrasound Med 1994;13:259-66.

16. Ahmed A, Tom, B, Calabrese, P. Ectopic pregnancy diagnosis and the pseudo-sac. Fertil Steril 2004;81:1225-8.

17. Condous G, Okaro E, Alkatib M, Khalid A, Rao S, Bourne T. Should an ectopic pregnancy always be diagnosed using transvaginal ultrasonography in the first trimester prior to surgery? Ultrasound Obstet Gynecol 2003;22(Suppl 1):53.

18. Maymon R, Halperin R, Mendlovic S, Schneider D, Vaknin Z, Herman A, Pansky M. Ectopic pregnancies in caesarean section scars: the 8-year experience of one medical centre. Hum Reprod 2004; 19:278-84.

19. Seow K, Huang L, Lin Y, Yan-Sheng M, Tsai Y. Cesarean scar pregnancy: issues in management. Ultrasound Obstet Gynecol 2004;23:247-53.

20. Jurkovic D, Hillaby K, Woelfer B, Lawrence A, Salim R, Elson C. First-trimester diagnosis and management of pregnancies implanted into the lower uterine segment Cesarean section scar. Ultrasound Obstet Gynecol 2003;21:220-7.

21. Vial Y, Petignat P, Hohlfeld P. Pregnancy in a caesarean scar pregnancy. Ultrasound Obstet Gynecol 2000;16:592-3.

22. Strandell A, Thorburn J, Hamberger L. Risk factors for ectopic pregnancy in assisted reproduction. Fertil Steril 1999;71:282-6.

23. Rojansky N, Schenker JG. Heterotopic pregnancy and assisted reproduction: an update. J Assist Reprod Genet 1996;13:594601.

24. Rizk B, Tan SL, Morcos S, Riddle A, Brinsden P, Mason VA, Edwards RG. Heterotopic pregnancies after in vitro fertilization and embryo transfer. Am J Obstet Gynecol 1991;164:161-4.

25. Stovall TG, Ling FW, Carson SA, Buster JE. Nonsurgical diagnosis and treatment of tubal pregnancy. Fertil Steril 1990;54:537-8.

26. Barnhart K, Sammel MD, Chung K, Zhou L, Hummel AC, Guo $\mathrm{W}$. Decline of serum human chorionic gonadotropin and spontaneous complete abortion: defining the normal curve. Obstet Gynecol 2004;104:975-81.

27. Barnhart KT, Sammel MD, Rinaudo PF, Zhou L, Hummel AC, Guo W. Symptomatic patients with an early viable intrauterine pregnancy: hCG curves redefined. Obstet Gynecol 2004;104: 50-5.

28. Ankum W, Van der Veen F, Hamerlynck J, Lammes F. Laparoscopy: a dispensable tool in the diagnosis of ectopic pregnancy? Hum Reprod 1993;8:1301-6.

29. Mol BW, Hajenius PJ, Engelsbel S, Ankum WM, Van der Veen F, Hemrika DJ, Bossuyt PM. Serum human chorionic gonadotropin measurement in the diagnosis of ectopic pregnancy when transvaginal sonography is inconclusive. Fertil Steril 1998;70:972-81.

30. Cacciatore B, Stenman U, Pekka Y. Diagnosis of ectopic pregnancy by vaginal ultrasonography in combination with a discriminatory serum hCG level of 1000 IU/1 (IRP). Br J Obstet Gynaecol 1990;97:904-8.

31. Barnhart KT, Katz I, Hummel A, Gracia CR. Presumed diagnosis of ectopic pregnancy. Obstet Gynecol 2002;100:505-10.

32. Kadar N, Bohrer M, Kemmann E, Shelden R. The discriminatory human chorionic gonadotropin zone for endovaginal sonography: a prospective, randomized study. Fertil Steril 1994;61:10611120.

33. Gracia C, Barnhart KT. Diagnosing ectopic pregnancy: decision analysis comparing six strategies. Obstet Gynecol 2001;97:46470 .

34. Jurkovic D, Bourne TH, Jauniaux E, Campbell S, Collins WP. Transvaginal color Doppler study of blood flow in ectopic pregnancies. Fertil Steril 1992;57:68-73.

35. Kirchler HC, Seebacher S, Alge AA, Mulller-Holzner E, Fessler $\mathrm{S}$, Kolle D. Early diagnosis of tubal pregnancy: changes in tubal blood flow evaluated by endovaginal color Doppler sonography. Obstet Gynecol 1993;82:561-5.

36. Salim A, Zalud I, Farmakides G, Schulman H, Kurjak A, Latin V. Corpus luteum blood flow in normal and abnormal early pregnancy: valuation with transvaginal color and pulsed Doppler sonography. J Ultrasound Med 1994;13:971-5.

37. Atri M. Ectopic pregnancy versus corpus luteum cyst revisited: best Doppler predictors. J Ultrasound Med 2003;22:1181-4.

38. Megier P, Desroches A. Color and pulsed Doppler ultrasonography imaging of tubal ectopic pregnancy: study of 100 cases. J Radiol 2003;84:1753-6.

39. Ramanan RV, Gajaraj J. Ectopic pregnancy - the leash sign. A new sign on transvaginal Doppler ultrasound. Acta Radio 2006;47:529-35.

40. Chou MM, Tseng JJ, Yi YC, Chen WC, Ho ES. Diagnosis of an interstitial pregnancy with 4-dimensional volume contrast imaging. Am J Obstet Gynecol 2005;193:1551-3.

41. Izquierdo LA, Nicholas MC. Three-dimensional transvaginal sonography of interstitial pregnancy. J Clin Ultrasound 2003;31:484-7.

42. Rempen A. The shape of the endometrium evaluated with threedimensional ultrasound: an additional predictor of extrauterine pregnancy. Human Reprod 1998;13:450-4. 